NASA/TM-2000-209767

\title{
Technology Development for a Stirling Radioisotope Power System for Deep Space Missions
}

Lanny G. Thieme

Glenn Research Center, Cleveland, Ohio

Songgang Qiu and Maurice A. White

Stirling Technology Company, Kennewick, Washington 
The NASA STI Program Office ... in Profile

Since its founding, NASA has been dedicated to the advancement of aeronautics and space science. The NASA Scientific and Technical Information (STI) Program Office plays a key part in helping NASA maintain this important role.

The NASA STI Program Office is operated by Langley Research Center, the Lead Center for NASA's scientific and technical information. The NASA STI Program Office provides access to the NASA STI Database, the largest collection of aeronautical and space science STI in the world. The Program Office is also NASA's institutional mechanism for disseminating the results of its research and development activities. These results are published by NASA in the NASA STI Report Series, which includes the following report types:

- TECHNICAL PUBLICATION. Reports of completed research or a major significant phase of research that present the results of NASA programs and include extensive data or theoretical analysis. Includes compilations of significant scientific and technical data and information deemed to be of continuing reference value. NASA's counterpart of peerreviewed formal professional papers but has less stringent limitations on manuscript length and extent of graphic presentations.

- TECHNICAL MEMORANDUM. Scientific and technical findings that are preliminary or of specialized interest, e.g., quick release reports, working papers, and bibliographies that contain minimal annotation. Does not contain extensive analysis.

- CONTRACTOR REPORT. Scientific and technical findings by NASA-sponsored contractors and grantees.
- CONFERENCE PUBLICATION. Collected papers from scientific and technical conferences, symposia, seminars, or other meetings sponsored or cosponsored by NASA.

- SPECIAL PUBLICATION. Scientific, technical, or historical information from NASA programs, projects, and missions, often concerned with subjects having substantial public interest.

- TECHNICAL TRANSLATION. Englishlanguage translations of foreign scientific and technical material pertinent to NASA's mission.

Specialized services that complement the STI Program Office's diverse offerings include creating custom thesauri, building customized data bases, organizing and publishing research results ... even providing videos.

For more information about the NASA STI Program Office, see the following:

- Access the NASA STI Program Home Page at http://www.sti.nasa.gov

- E-mail your question via the Internet to help@sti.nasa.gov

- Fax your question to the NASA Access Help Desk at (301) 621-0134

- Telephone the NASA Access Help Desk at (301) 621-0390

- Write to:

NASA Access Help Desk NASA Center for AeroSpace Information 7121 Standard Drive Hanover, MD 21076

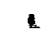


NASA/TM-2000-209767

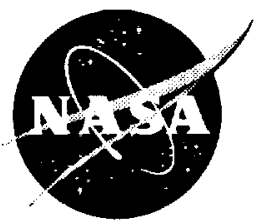

\section{Technology Development for a Stirling Radioisotope Power System for Deep Space Missions}

Lanny G. Thieme

Glenn Research Center, Cleveland, Ohio

Songgang Qiu and Maurice A. White

Stirling Technology Company, Kennewick, Washington

Prepared for the

34th Intersociety Energy Conversion Engineering Conference sponsored by the Society of Automotive Engineers

Vancouver, British Columbia, Canada, August 1-5, 1999

National Aeronautics and

Space Administration

Glenn Research Center 
Trade names or manufacturers' names are used in this report for identification only. This usage does not constitute an official endorsement, either expressed or implied, by the National Aeronautics and Space Administration.

Available from

NASA Center for Aerospace Information 7121 Standard Drive

Hanover, MD 21076

Price Code: A03
National Technical Information Service 5285 Port Royal Road Springfield, VA 22100 Price Code: A03 


\title{
Technology Development for a Stirling Radioisotope Power System for Deep Space Missions
}

\author{
Lanny G. Thieme \\ National Aeronautics and Space Administration \\ Glenn Research Center \\ Cleveland, Ohio 44135 \\ and \\ Songgang Qiu and Maurice A. White \\ Stirling Technology Company \\ Kennewick, WA 99336
}

\begin{abstract}
NASA Glenn Research Center and the Department of Energy (DOE) are developing a Stirling convertor for an advanced radioisotope power system to provide spacecraft on-board electric power for NASA deep space missions. NASA Glenn is addressing key technology issues through the use of two NASA Phase II SBIRs with Stirling Technology Company (STC) of Kennewick, WA. Under the first SBIR, STC demonstrated a 40 to 50 fold reduction in vibrations, compared to an unbalanced convertor, with a synchronous connection of two thermodynamically independent free-piston Stirling convertors. The second SBIR is for the development of an Adaptive Vibration Reduction System (AVRS) that will essentially eliminate vibrations over a mission lifetime, even in the unlikely event of a failed convertor. This paper discusses the status and results for these two SBIR projects and also presents results for characterizing the friction factor of high-porosity random fiber regenerators that are being used for this application.
\end{abstract}

\section{Introduction}

NASA Glenn Research Center and the Department of Energy (DOE) are developing a Stirling convertor for an advanced radioisotope power system to provide spacecraft on-board electric power for NASA deep space missions. Stirling is being evaluated as an alternative to replace Radioisotope Thermoelectric Generators (RTGs) with a high-efficiency power source. The efficiency of the Stirling system, in excess of 20 percent, will reduce the necessary isotope inventory by a factor of 3 or more compared to RTGs. Stirling is the most developed convertor option of the advanced power concepts under consideration [1,2].

DOE is developing the radioisotope Stirling convertor under contract with Stirling Technology Company (STC) of Kennewick, WA [3,4]. Two 55-We convertors are now being tested in a dynamically-balanced opposed arrangement. A single convertor is shown in figure 1 while figure 2 shows a pair of convertors on test. NASA Glenn is providing technical consulting for this effort under an Interagency Agreement with DOE.

The design of the 55-We Stirling convertor is based on previous successful STC development efforts, particularly those for the 10-We RG-10 radioisotope terrestrial convertor and the 350-We RG-350 aimed at commercial cogeneration and remote power [5]. STC has developed product lines for both power sources and cryocoolers. A remote power generator set with the RG-350 is shown in figure 3. One RG-10 has now been on life test for over 50,000 hours (5.7 years) with no convertor maintenance and no degradation in performance. Two RG-10 convertors are awaiting isotope fueling and subsequent field testing. Multiple units of the RG-350 and their companion BeCOOL cryocoolers have accumulated over 60,000 total hours of operation, much of this at independent third-party test sites. Finally, STC has also completed extensive component life testing and, in particular, has over 1000 years of total test time ( 230 flexures) on the critical flexural bearings. These numerous test hours on various systems and on key components provide a high confidence that the 55-We convertor will meet its life and reliability goals.

The 55-We convertor uses the following proven STC long life design approaches: non-contacting moving parts with flexural bearings and non-contacting clearance seals, no lubrication, an integral alternator inside the pressure vessel, hermetic sealing, and Inconel 718 for the hot-end material. The use of Inconel 718 allows the necessary long lifetimes at a hot-end temperature of $650{ }^{\circ} \mathrm{C}$. Increased efficiency and/or decreased radiator size can be achieved by using advanced hot-end materials operating at a higher temperature.

As part of the overall radioisotope Stirling development, NASA Glenn is addressing key technology issues through the use of two NASA Phase II Small 


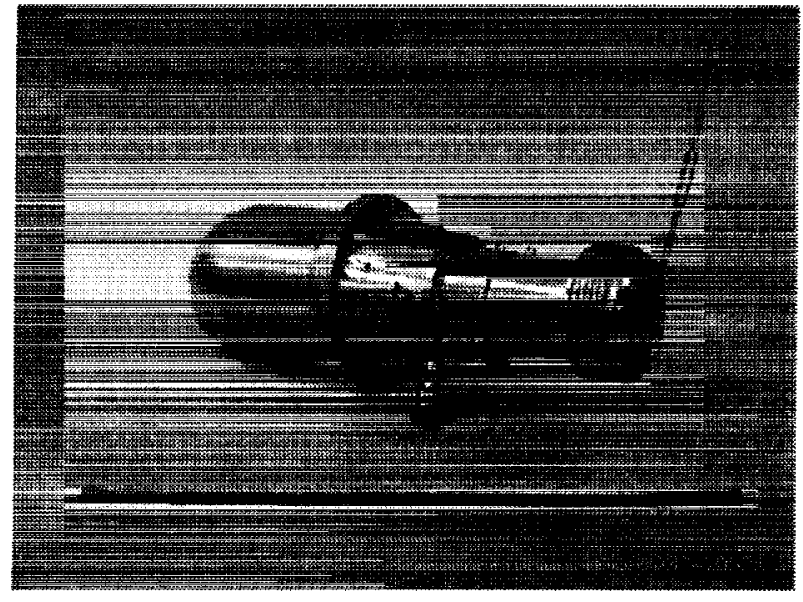

Figure 1.-DOE/STC 55-We convertor.

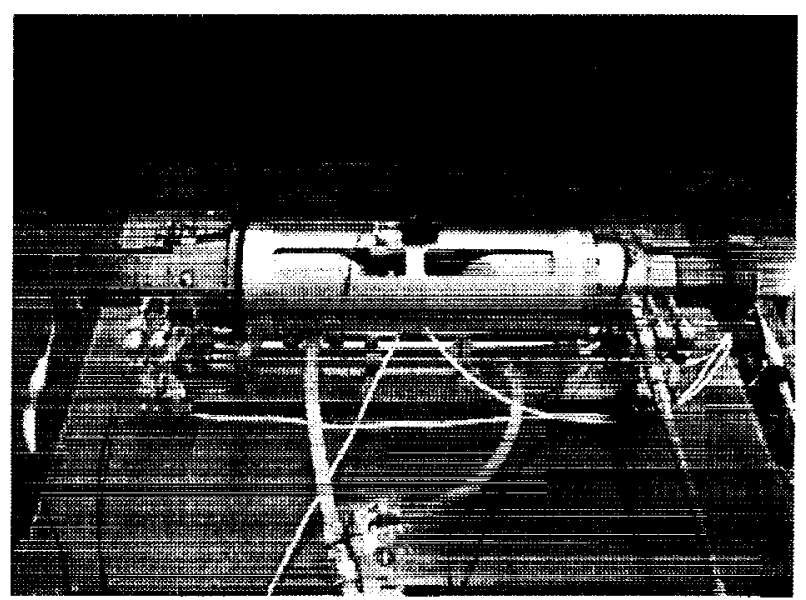

Figure 2.-Two opposed 55-We convertors on test.

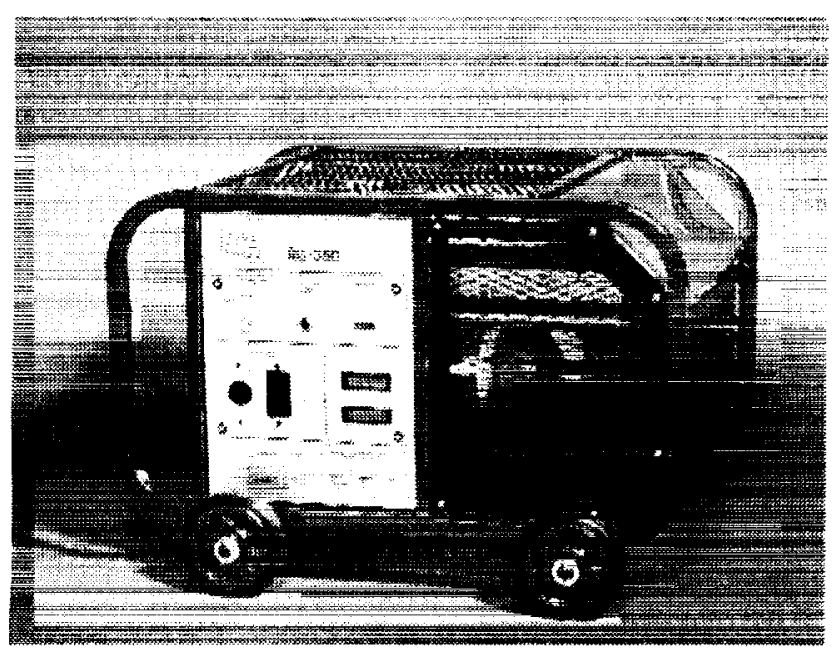

Figure 3.-350-We RG-350 remote power generator set.
Business Innovation Research (SBIR) contracts with STC. Under the first SBIR, STC demonstrated a synchronous connection of two thermodynamically independent Stirling convertors and a 40 to 50 fold reduction in vibrations compared to an unbalanced convertor. This connection method is now being used to connect the DOE/STC 55-We convertors. The second SBIR contract is for the development of an Adaptive Vibration Reduction System that will essentially eliminate vibrations over a mission lifetime and will have the ability to adjust to any changing convertor conditions over the course of the mission.

NASA Glenn has been investigating Stirling isotope power systems for deep space missions since about 1990. This work grew out of earlier Stirling efforts conducted for DOE for a Stirling automotive engine and for the NASA Civil Space Technology Initiative (CSTI) to develop Stirling for a nuclear power system to provide electrical power for a lunar or Mars base. NASA Glenn also provided technical management for DOE for the Advanced Stirling Conversion System (ASCS) terrestrial dish Stirling project. Overall, NASA Glenn has been developing Stirling technologies since the mid-1970's.

In support of DOE, Orbital Sciences Corporation (OSC) has completed system studies for a Stirling radioisotope power system for deep space missions [6,7]. The system was based on a STC Stirling convertor design. OSC has analyzed power system layouts using either two or four convertors and conceptualized the GPHS and radiator interfaces. The choice of two or four convertors per power system is dependent, in part, on system redundancy requirements. One possible OSC system configuration is shown in figure 4. Lockheed Martin is also now evaluating Stirling radioisotope power system designs for DOE.

Systems using Stirling convertors are also being analyzed by NASA Glenn for other space applications including solar dynamic power systems for space-based radar [8] and as a deep space alternative to the radioisotope system, a combined electrical power and cooling system for a Venus lander, and lunar/Mars bases and rovers.

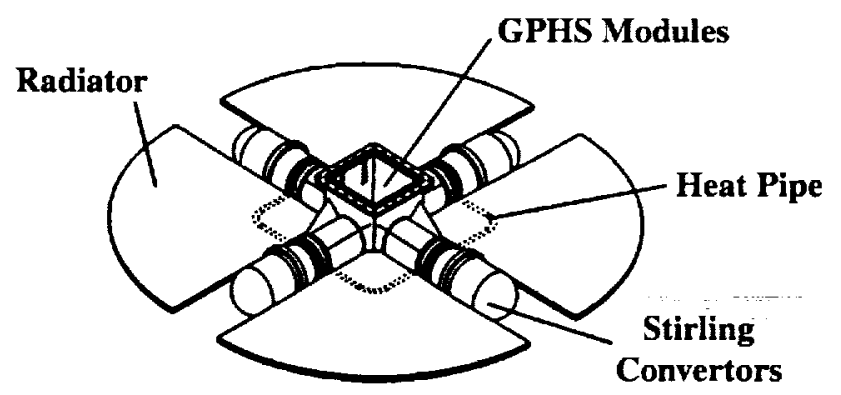

Figure 4.-Orbital Sciences Corp. system concept [7]. 


\section{Synchronous Operation of Opposed Stirling Convertors}

STC, as part of a NASA Phase II SBIR contract, has successfully demonstrated synchronous operation of two thermodynamically independent free-piston Stirling convertors with linear alternators connected electrically in parallel. Previous Stirling development had focused on single convertors and had not addressed how to connect multiple convertors in a system. However, in most potential space applications, multiple convertors are important for redundancy and modularity. Thermodynamically independent convertors may allow one convertor to fail without affecting the performance of the other. Finally, the use of multiple convertors is important to controlling vibrations, a critical issue for a dynamic space power system. Synchronization of convertor pairs operating in an opposed configuration provides balanced operation with minimal vibration.

Two RG-350 convertors were used for this development. Initial efforts included computer simulations of multipleconvertor connection methods and single-convertor baseline testing of each of the RG-350 convertors. Each convertor was tested separately over a range of hot-end and cold-end temperatures and charge pressures. Approximately $5 \mathrm{~g}$ 's vibration was measured at the nominal conditions for a single convertor.

During multiple-convertor testing, synchronization was achieved with the two convertors (see figure 5) operating over a wide range of conditions. The frequency of each convertor was identical, and the pistons operated nominally 180 degrees out-of-phase mechanically. The convertors were connected electrically in parallel and mechanically through external attachments on the coldend pressure vessels. A mechanical coupler was developed that aligns the two convertors and can compensate for any inherent misalignments. Synchronization produced a 40 to 50 fold reduction in vibrations compared to an unbalanced convertor, a value that appears to be well below pixel smear limits for deep space sensing. Equal power generation between the two convertors was also demonstrated under nominal conditions. This connection method is now being used to connect the DOE/STC 55-We convertors.

The synchronization was shown to be very robust by testing at conditions of simulated degradation and by transient testing. For one set of runs, the average hot-end temperature of one convertor was varied widely while holding the other convertor hot-end temperature nearly constant at about $600{ }^{\circ} \mathrm{C}$. Synchronization was maintained over this range, and figure 6 shows the effects on the phase difference between the power pistons and the maximum vibration measured on the two convertors. Zero-degree phase lag indicates the pistons are operating 180 degrees out-of-phase mechanically. The maximum vibration increased from $0.12 \mathrm{~g}$ to just $0.48 \mathrm{~g}$ over this wide range of operation; this is compared to about $5 \mathrm{~g}$ 's vibration for an unbalanced convertor. The convertor

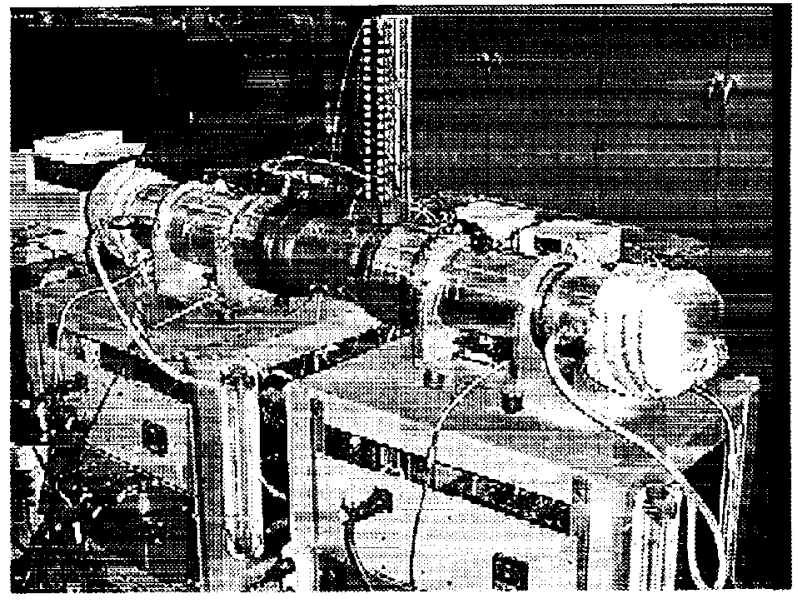

Figure 5.-Stirling convertors synchronized for system operation with low vibrations.

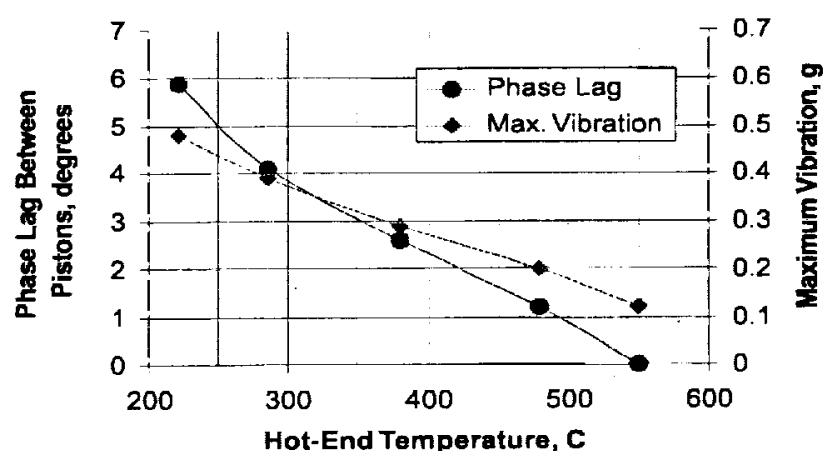

Figure 6.-Response of the maximum vibration and phase lag between pistons when the hot-end temperature of one convertor of a fully coupled pair is varied.

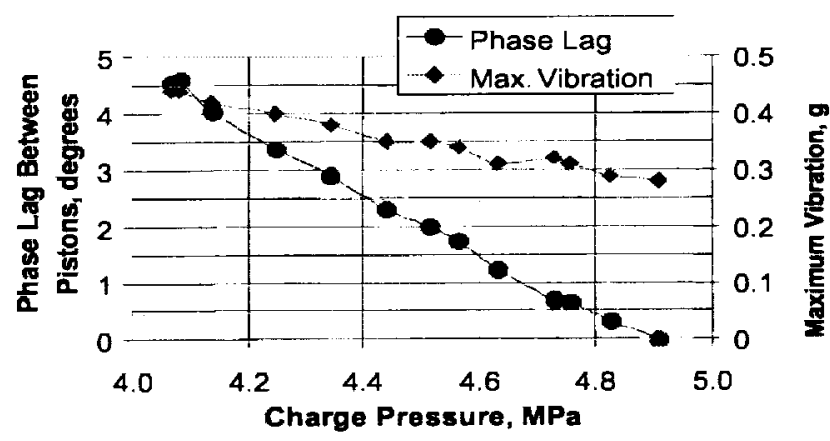

Figure 7.-Response of the maximum vibration and phase lag between pistons when the charge pressure of one convertor of a fully coupled pair is varied.

power output at the lowest temperature was about 20 percent of the power output for the convertor operating at about $600{ }^{\circ} \mathrm{C}$.

Charge pressure variations of up to 20 percent for one convertor while maintaining constant charge pressure in the other and constant power input to each were also tested. Results for this case are shown in figure 7. Again, synchronization was maintained, and only small increases 
in vibration were measured. These tests were run with an earlier version of the mechanical coupler so the vibration levels are somewhat higher than those shown in figure 6. Power output remained essentially the same for each convertor over this range; this was as expected from the single-convertor test results.

Transient data taken during various connections and disconnections of the two convertors showed the ability to achieve synchronization reliably and rapidly. No significant transient overstrokes were seen or any other potentially damaging results. Figure 8 shows transient traces for the piston and displacer motions, voltage, current, and vibrations from one convertor when the other convertor is disconnected and shut down. The convertors are synchronized at nominal conditions at the beginning of the transient. The only noticeable effect is the increase in the vibrations of the now electrically uncoupled convertors.

Some transient effects were found when the two convertors were connected while operating at nominal conditions. Typically, an acceleration spike to about 6 to $10 \mathrm{~g}$ 's was seen and may be due to the two convertors being briefly in-phase mechanically after the coupling. This transient settled out in about 15 cycles $(1 / 4 \mathrm{sec}$.), after which the vibration level was stable at the very low values achieved with synchronization. If necessary, this transient could be mitigated by adding an extra load briefly on the alternator output while connecting the convertors to dampen the piston motions during the transient.

Successful system operation was demonstrated with the two synchronized convertors feeding a battery charger load, as would most likely be used in a radioisotope power system. Four standard automotive batteries were connected in series and tests run over a range of convertor hot-end temperatures and battery state-of-charge. Operation was found to be essentially the same as when dissipating power to the controller internal load resistors.

Voltage

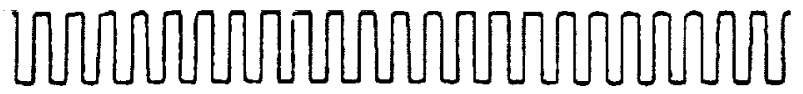

Current

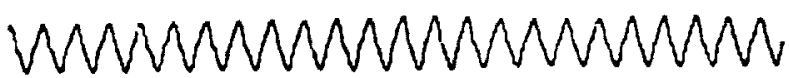

Piston and Displacer Positions

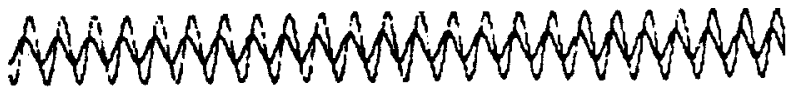

Vibrations

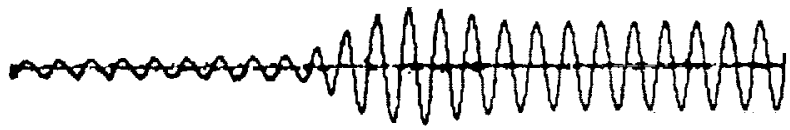

Figure 8.-Transient response when the parallel electrical connection is broken and one convertor is shut down.
Tests were also run with the electrical coupling only and with the mechanical coupling only. With only the electrical coupling, the convertors synchronized as before; however, there was no reduction in vibrations as there was no mechanical connection between the convertors. With only the mechanical coupling, there was at most a weak synchronous connection, and the vibrations were similar to a single unbalanced convertor.

A further innovation during this SBIR project was the demonstration of an artificial neural network (ANN) that could potentially monitor the health of a convertor using only non-invasive instrumentation that does not penetrate the convertor pressure vessel. The ANN successfully predicted piston and displacer amplitudes and phasing for a 10-We RG-10 convertor using voltage, current, and rejection temperature as the only inputs. Simulated pressure degradation for one of the fully coupled RG-350 convertors was also successfully tracked using current, currentvoltage phasing, and output power for each convertor as inputs. It is felt that the ANN has a high probability of detecting any convertor degradation that may occur without needing any internal instrumentation that would decrease the convertor reliability. This could then allow the system controller to adjust operation to maximize system performance.

\section{Adaptive Vibration Reduction System}

Under a second NASA Phase II SBIR, STC is developing an Adaptive Vibration Reduction System (AVRS) that will further reduce vibration levels by a factor of 10 or more under normal operating conditions. It will achieve this with an active balance system with feedback from a vibration signal and will cancel the fundamental vibration and up to 10 harmonics. Even more importantly, the AVRS will be adaptive and will add the ability to adjust to any changing convertor conditions over the course of a mission. Thus, it should allow successful dynamic balancing over the mission lifetime and will be able to demonstrate its adaptive ability through up-front testing. The AVRS is now being developed on two RG-350 convertors and will also be demonstrated on the DOE/STC 55-We convertors.

The AVRS will use a balance mass driven by a separate linear motor; only one balance mass and motor are needed for two opposed Stirling convertors. A balance mass and motor to be used in the first AVRS testing with the RG-350 convertors is shown in figure 9. The vibration signal will be measured with either a load cell or an accelerometer. A fast Fourier transform of this signal will then be used to construct a compensation signal that will be sent to the balance motor through a power amplifier. Both the amplitude and phase of each harmonic will be adjusted. The motion of the balance mass center-ofgravity will be opposed to and proportional to the motion of the center-of-gravity of the combined system of two pistons and two displacers. The AVRS will adjust to any 


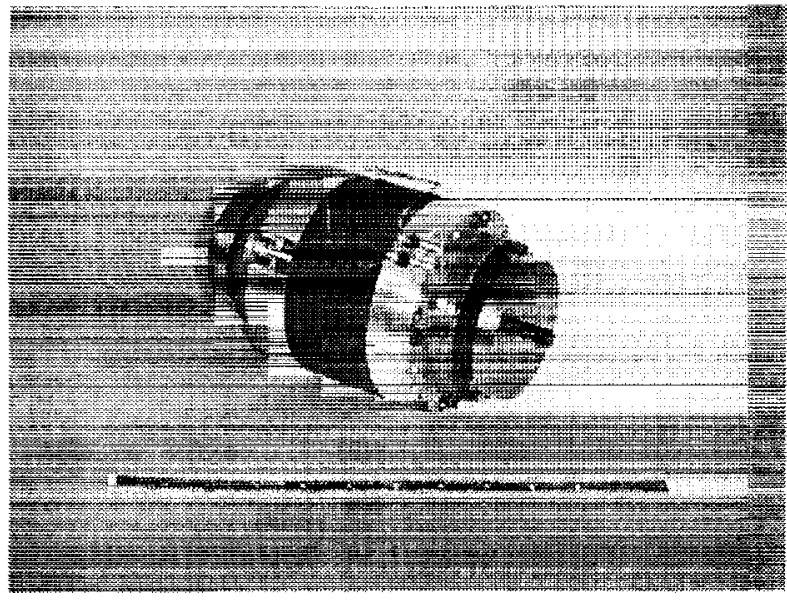

Figure 9.-AVRS balance mass and motor for RG-350 testing.

change in convertor operating conditions, any convertor degradation that may occur over a mission, or even in the unlikely event of a failed convertor.

Stirling cryocoolers are currently used to cool vibrationsensitive sensors in space applications. STC has demonstrated a cryocooler vibration level of only $0.007 \mathrm{~g}$ 's using similar technology to the AVRS. This technique has been shown to be effective with reasonable power and mass budgets. One key difference for balancing power convertors is that the frequency is not fixed as it is in coolers. Thus, the frequency must be measured on a continual basis and factored into the control algorithm.

A further task of this contract will demonstrate a passive heat rejection system for the 55 -We convertor. A copper/water heat pipe was used in the OSC system concept shown in figure 4 to transport the convertor's rejected heat to the radiator.

\section{Friction Factor Characterization for High-Porosity Random Fiber Regenerators}

As part of the Interagency Agreement with DOE, NASA Glenn performed a review of the DOE/STC 55-We convertor design. This review included modeling the convertor performance with the HFAST Stirling code and comparing the results to the predictions from the GLIMPS code used by STC to design the convertor. The two codes predicted similar convertor performance when the regenerator friction factors were adjusted to be similar for each code. Without this adjustment, the regenerator friction factor correlations and consequent pressure drop losses showed significant differences at the high regenerator porosities (90 to 96 percent) being considered for this low-power convertor design.

Both GLIMPS and HFAST include a porosity dependence in their friction factor correlations. However, HFAST has a much higher sensitivity to this than does GLIMPS, for both screen and random fiber regenerators. Consequently, the HFAST friction factor for a 94 percent porosity regenerator was nearly an order of magnitude larger for screens and about 40 percent larger for random fibers than that used by GLIMPS over most of the Reynolds number range. The friction factor correlations for both codes agree well at $7 \overline{8}$ percent porosity for both types of regenerators.

Gedeon, in his final report on regenerator pressure drop and heat transfer testing in oscillating flow at Ohio University [9], concluded that he could not determine any porosity dependence for the range of screens and felts (random fiber) that were tested in that project. These covered porosities of 62 to 78 percent for screens and 69 to 84 percent for felts. The HFAST manual states that its screen regenerator friction factor is based on Kays and London data and appears to be the same as used in an earlier version of GLIMPS. Kays and London show that their test data were taken for a range of porosities of 60 to 83 percent for screens [10]. GLIMPS (version 4.0) now uses relationships that are based, in part, on earlier testing at Ohio University [11]. Pressure drop tests for steady and oscillating flow were also completed by Sunpower, Inc. with the same rigs that were later moved to Ohio University [12]. These tests included regenerator porosities of 61 to 68 percent for screens and 80 to 84 percent for random fibers.

So it appears that neither code's friction factor correlations are based on any regenerator test data at the porosities that were being considered for the regenerator of the Stirling radioisotope convertor. Due to this concern, NASA Glenn recommended that a steady-flow pressure drop test be completed on a high-porosity regenerator sample to get good empirical data on the friction factor for these regenerators. Heat transfer test data would also be very important but are much more difficult to obtain. It was felt that the straightforward pressure drop tests would give at least some idea of the similarity of high-porosity regenerators to those for which both friction factor and heat transfer data exist.

STC selected and then fabricated three random fiber regenerator test samples, one each at approximately 80 , 88 , and 96 percent porosities. The wire diameter used in all samples was 0.0009 in. (22 microns). A photomicrograph of a section of the 96 percent porosity sample is shown in figure 10 . The 80 percent porosity sample was chosen to give a comparison to the correlations used in GLIMPS and HFAST at a porosity level where they are based on existing test data. STC also designed a test fixture, with inputs from NASA Glenn, and then fabricated this fixture to hold the samples for testing. Finally, STC provided their desired flow rates for test.

Testing was done at the Flow Calibration Laboratory at NASA Glenn with air at 100-psia inlet pressure for all samples. Flow conditions were chosen to cover the range of Reynolds numbers that are expected to occur in the Stirling radioisotope convertor and to include higher flow rates that may be applicable to future convertor designs. Tests were also run for the 96 percent porosity sample at 55-psia inlet pressure to check the effect of DP/P and in 


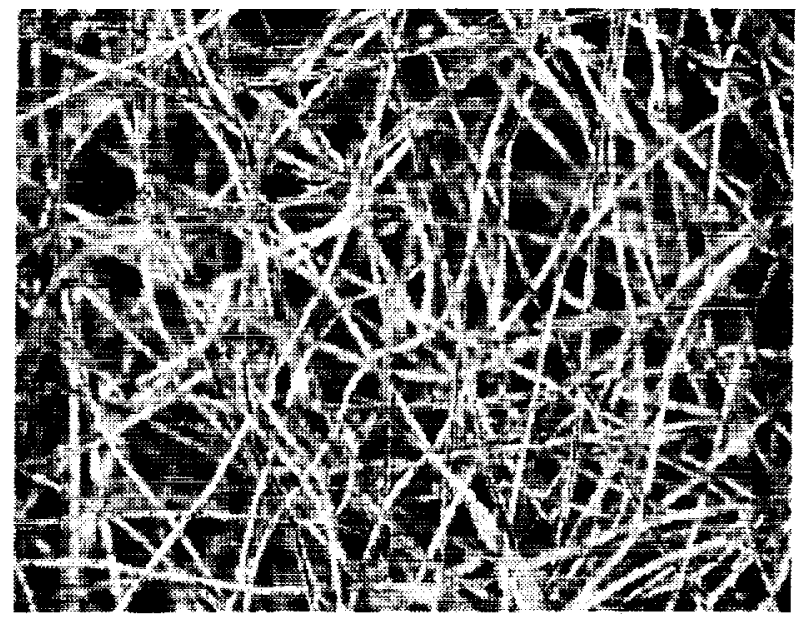

Figure 10.-Photomicrograph of 96 percent porosity random fiber regenerator sample.

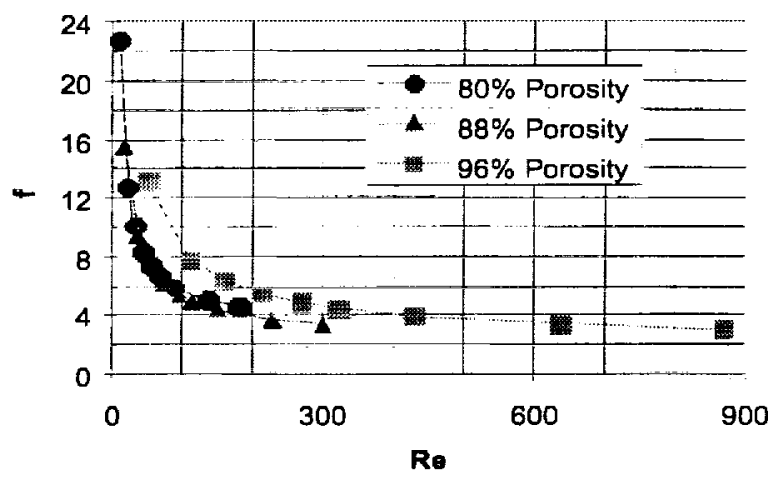

Figure 11.-Friction factor, $f$, vs. Reynolds number, Re, for random fiber regenerator samples.

the reverse flow direction (which showed no difference in test results).

The measured flow data were provided to STC. STC and NASA Glenn first independently reduced this data to friction factor and Reynolds number and then resolved any significant differences. Friction factor versus Reynolds number (based on NASA Glenn's data reduction) is shown for each of the samples in figure 11. It can be seen that the curves for the 80 and 88 percent porosity samples are very similar while the friction factor is significantly higher for the 96 percent porosity sample.

The friction factor curves for the 80 and 96 percent porosity samples are compared with three correlations in figures 12 and 13. The three correlations are the GLIMPS and HFAST random fiber correlations and the latest correlation based on test data taken at Ohio University [9]. All three correlations agree well with the test data for the 80 percent porosity sample. For the 96 percent porosity sample, HFAST compares the best with the test data (data shown is for 100-psia inlet pressure only) at the lower Reynolds numbers, 0 to 300 , which was the expected range for the Stirling radioisotope convertor design. However, for the 88 percent porosity sample, the

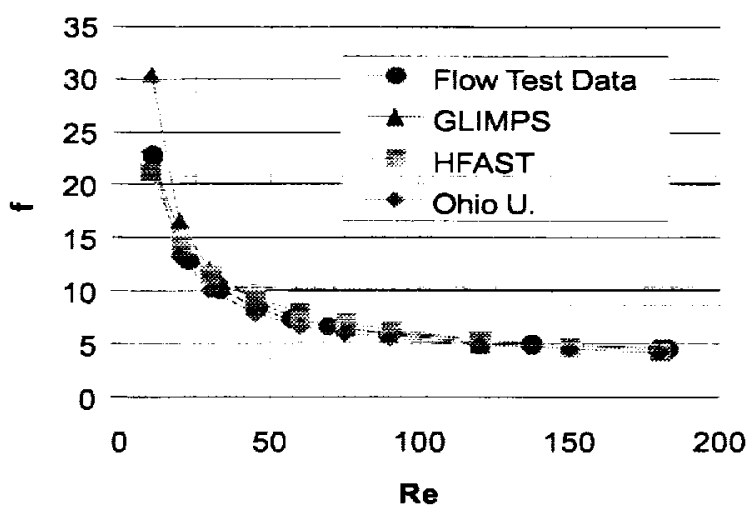

Figure 12.-Friction factor, $f$, vs. Reynolds number, $\mathrm{Re}$, for 80 percent porosity random fiber regenerator sample-comparison of test data with correlations.

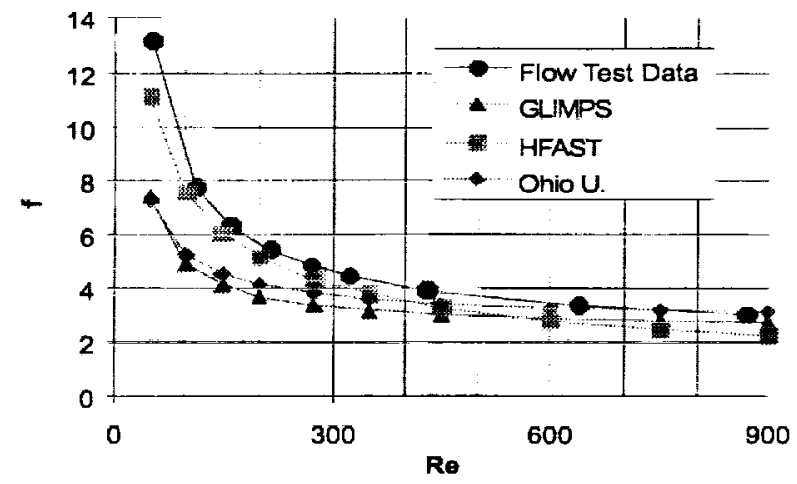

Figure 13.-Friction factor, $f$, vs. Reynolds number, Re, for 96 percent porosity random fiber regenerator sample-comparison of test data with correlations.

GLIMPS and Ohio University correlations compared the best with the test data while the HFAST correlation yielded a higher friction factor (results not shown).

Following analyses of these results, STC decided to use the GLIMPS correlation for all regenerator porosities up to 88 percent. They then derived a relationship based on the GLIMPS friction factor for 88 percent porosity and the 96 percent porosity test data (average of the curves for 55- and 100-psia inlet pressures) that interpolates between these for porosities from 88 to 96 percent. Figure 14 shows the GLIMPS friction factor curve for 88 percent porosity and the two test data curves for the 96 percent porosity sample over the Reynolds number range of 0 to 350 .

STC GLIMPS results with the new friction factor input for 88 to 96 percent porosities showed that the final optimized regenerator design porosity was reduced from the previous 96 percent to 90 percent. This 90 percent porosity was then used for the actual 55-We convertor. It should be kept in mind that no adjustments were made to the heat transfer correlation used in GLIMPS for the higher porosities. NASA Glenn is now setting up a regenerator test rig for another project that could potentially 


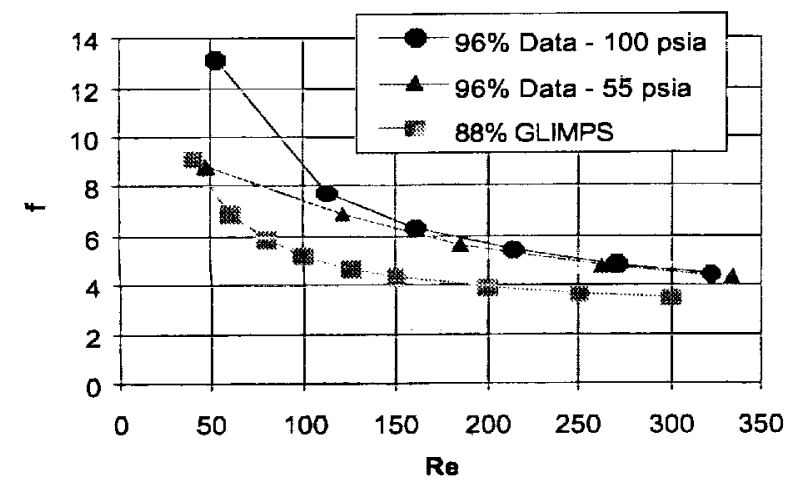

Figure 14.--Input curves for STC correlation for random fiber regenerator friction factor for porosities between 88 percent and 96 percent.

perform heat transfer testing on high-porosity random fiber regenerator samples.

\section{NASA Glenn Supporting Technology Development Plans for the Stirling Radiois otope Convertor}

Plans have been proposed for further Stirling technology development at NASA Glenn in support of developing the Stirling radioisotope power system for deep space missions. Identified tasks include controls development and performance verification through inhouse testing of RG-350 and 55-We Stirling convertors, structural life assessment of the Stirling heater head, materials and joining evaluations, finite element analysis (FEA) of a lightweight linear alternator concept, thermal aging tests of the linear alternator permanent magnets, demonstrating convertor operation under launch and orbit transfer load conditions, and a radiator conceptual design. The vibration test facility of the Structural Dynamics Laboratory at NASA Glenn is shown in figure 15. This facility will be used for any testing under launch and orbit transfer loads. These proposed tasks build on NASA Glenn expertise developed as part of previous Stirling research, especially for the Stirling space power development during the NASA CSTI project [13-15]. These tasks were identified in the appropriate areas where value-added development is provided as part of the overall Stirling radioisotope effort.

\section{Summary and Concluding Remarks}

NASA Glenn Research Center and the Department of Energy are developing a Stirling convertor for an advanced radioisotope power system to provide spacecraft on-board electric power for NASA deep space missions. Stirling is being evaluated as an alternative to replace

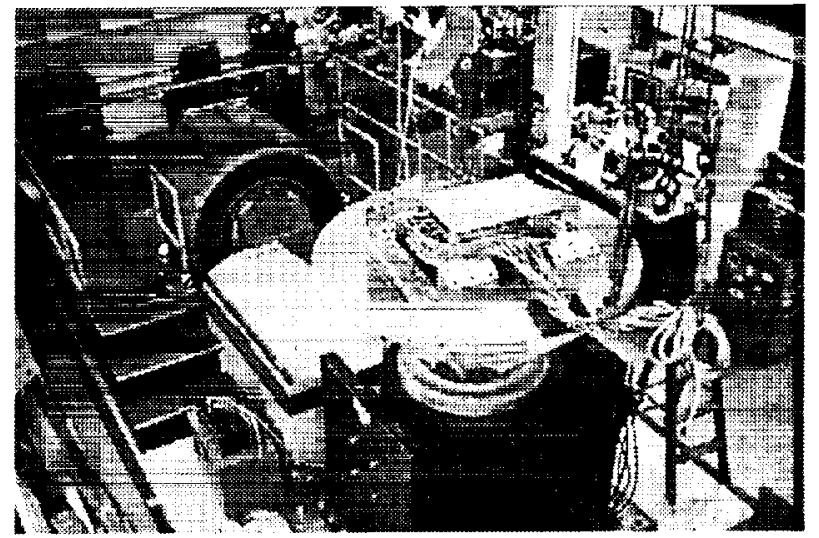

Figure 15.-Vibration Test Facility at NASA Glenn.

RTGs with a high-efficiency power source. STC, under contract to DOE, is making rapid progress in developing and demonstrating the 55-We convertor. Two 55-We convertors are now operating in a dynamically-balanced opposed arrangement, and full electrical power output is expected to be achieved by early summer 1999. Preliminary efficiency indications are also very encouraging. In addition, STC's numerous test hours on various related systems and key components provide a high confidence that the 55-We convertor will meet its life and reliability goals.

NASA Glenn is addressing key technology issues through the use of two NASA Phase II SBIRs with STC. Under the first SBIR, STC demonstrated a synchronous connection of two 350 -We thermodynamically independent Stirling convertors. STC achieved synchronization of the two convertors over a wide operating range, showed a 40 to 50 fold reduction in vibrations compared to an unbalanced convertor, and proved the connection to be robust and reliable through numerous transient tests. This connection method is now being used to connect the DOE/STC 55-We convertors. The second SBIR is for the development of an Adaptive Vibration Reduction System (AVRS) that will essentially eliminate vibrations over a mission lifetime, even in the unlikely event of a failed convertor. The AVRS will further reduce vibrations by a factor of 10 or more under normal operating conditions and, even more importantly, will add the ability to adjust to any changing convertor conditions over the course of a mission. Balance motors have been fabricated and baseline tests completed; initial testing of the AVRS is expected to begin shortly.

In support of the design effort for the 55-We convertor, NASA Glenn and STC determined the friction factor characteristics of high-porosity random fiber regenerators. Results for a 96 percent porosity regenerator sample were found to vary significantly from those for 80 and 88 percent porosity samples. The results at 80 and 88 percent porosity agreed well with the correlation used in the GLIMPS computer code. STC derived a revised correlation for random fiber regenerators with porosities between 88 and 96 percent based on these results. New 
optimizations with this correlation led to changing their regencrator design porosity from 96 to 90 percent.

Plans have been proposed by NASA Glenn to provide further support for the Stirling radioisotope power system development in the areas of convertor, component, and materials testing. Specific areas identified include convertor performance verification, controls development for multiple convertors and multiple system loads, heater head structural life assessment, materials and joining evaluations, magnet thermal aging tests, and demonstration of convertor operation under launch and orbit transfer load conditions.

\section{References}

[1] Frazier, T.A.: Advanced Conversion Technology Review Panel Report, Proceedings of the $33^{\text {rd }}$ Intersociety Energy Conversion Engineering Conference, Paper IECEC-98-398, 1998.

[2] Mondt, J.F. and Nesmith, B.J.: Advanced Convertor Technology Evaluation and Selection for ARPS, Proceedings of the Space Technology and Applications International Forum, 1998.

[3] White, M.A.; Qiu, S.; Erbeznik, R.M.; Olan, R.W.; and Welty, S.C.: Status of an Advanced Radioisotope Space Power System Using Free-Piston Stirling Technology, Proceedings of the $33^{\text {rd }}$ Intersociety Energy Conversion Engineering Conference, Paper IECEC-98-417, 1998.

[4White, M.A.; Qiu, S.; Olan, R.W.; and Erbeznik, R.M.: Technology Demonstration of a Free-Piston Stirling Advanced Radioisotope Space Power System, Proceedings of the Space Technology and Applications International Forum, 1999.

[5] Erbeznik, R.M. and White, M.A.: Test Results and Commercialization Plans for Long Life Stirling Generators, Proceedings of the $31^{\text {st }}$ Intersociety Energy Conversion Engineering Conference, Vol.2, pp. 1265-1270, 1996.
[6] Schock, Alfred; Or, Chuen T.; and Kumar, Vasanth: Radioisotope Power System Based on Derivative of Existing Stirling Engine, Proceedings of the $30^{\mathrm{th}}$ Intersociety Energy Conversion Engineering Conference, Vol. 1, pp. 649-656, 1995.

[7] Schock, Alfred; Or, Chuen,; and Kumar, Vasanth: Radioisotope Power System Based on Improved Derivative of Existing Stirling Engine and Alternator, Proceedings of the Space Technology and Applications International Forum, 1999.

[8] Mason, L.S.: Technology Projections for Solar Dynamic Power, NASA/TM-1999-208851, 1999.

[9] Gedeon, D. and Wood, J.G.: Oscillating-Flow Regenerator Test Rig: Hardware and Theory With Derived Correlations for Screens and Felts, NASA CR-198442, 1996.

[10] Kays, W.M. and London, A.L.: Compact Heat Exchangers, $2^{\text {nd }}$ Edition, McGraw-Hill, Inc., 1964.

[11] Gedeon, D. and Wood, J.G.: Oscillating-Flow Regenerator Test Rig: Woven Screen and Metal Felt Results, status report for NASA grant NAG3-1269, 1992.

[12] Koester, G.; Howell, S.; Wood, G.; Miller, E.; and Gedeon, D.: Oscillating Flow Loss Test Results in Stirling Engine Heat Exchangers, NASA CR-182288, 1990.

[13] Niedra, J.M.: Comparative M-H Characteristics of 1-5 and 2-17 Type Samarium-Cobalt Permanent Magnets to 300 C, NASA CR-194440, 1994.

[14] Abdul-Aziz, A.; Bartolotta, P.; Tong, M.; and Allen, G.: An Experimental and Analytical Investigation of Stirling Space Power Convertor Heater Head, NASA TM-107013, 1995.

[15] Rauch, J.S. and Kankam, M.D.: Transient and Steady-State Tests of the Space Power Research Engine with Resistive and Motor Loads, NASA TM-106832, 1995. 
Public reporting burden for this collection of information is estimated to average t hour per response, including the time for revlewing instructions, searching existing data sources, gathering end maintaining the data needed, and completing and reviewing the collection of intormation. Send comments regarding this burden estimate or any other aspect of this collection of information, including suggestions for reducing this burden, to Washington Headquarters Services, Directorate for Information Operations and Reports, 1215 Jefferson Davis Highway, Suite 1204, Arlington, VA 22202-4302, and to the Office of Management and Budget. Paperwork Feduction Project (0704-0188), Washington, DC 20503.
1. AGENCY USE ONLY (Leave blank) 2. REPORT DATE 3. REPOAT TYPE AND DATES COVEAED March 2000
Technical Memorandum

\section{TITLE AND SUBTITLE} 5. FUNDING NUMBERS

Technology Development for a Stirling Radioisotope Power System for Deep Space Missions

6. AUTHOR(S)

Lanny G. Thieme, Songgang Qiu, and Maurice A. White

7. PERFORMING OAGANIZATION NAME(S) AND ADDRESS(ES)

National Aeronautics and Space Administration

John H. Glenn Research Center at Lewis Field

Cleveland, Ohio 44135-3191
WU $-632-1 \mathrm{~A}-1 \mathrm{~K}-00$

8. PERFORMING ORGANIZATION REPORT NUMBER

E-12043

\section{SPONSORING/MONITORING AGENCY NAME(S) AND ADDRESS(ES)}

National Aeronautics and Space Administration

Washington, DC 20546-0001

10. SPONSORINGMONITORING AGENCY REPORT NUMBER

NASA TM--2000-209767

\section{SUPPLEMENTARY NOTES}

This is a modified version of a paper prepared for the 34th Intersociety Energy Conversion Engineering Conference sponsored by the Society of Automotive Engineers, Vancouver, British Columbia, Canada, August 1-5, 1999. Lanny G. Thieme, NASA Glenn Research Center; Songgang Qiu, and Maurice A. White, Stirling Technology Company, 4208 West Clearwater Avenue, Kennewick, Washington, 99336 (work funded by NASA Contracts NAS3-98016 and NAS3-27817). Responsible person, Lanny G. Thieme, organization code 5490, (216) 433-6119.

12a. DISTRIBUTION/AVAILABILITY STATEMENT

12b. DISTRIBUTION CODE

Unclassified - Unlimited

Subject Categories: 20 and 44

Distribution: Nonstandard

This publication is available from the NASA Center for AeroSpace Information, (301) 621-0390

\section{ABSTRACT (Maximum 200 words)}

NASA Glenn Research Center and the Department of Energy (DOE) are developing a Stirling convertor for an advanced radioisotope power system to provide spacecraft on-board electric power for NASA deep space missions. NASA Glenn is addressing key technology issues through the use of two NASA Phase II SBIRs with Stirling Technology Company (STC) of Kennewick, WA. Under the first SBIR, STC demonstrated a 40 to 50 fold reduction in vibrations, compared to an unbalanced convertor, with a synchronous connection of two thermodynamically independent free-piston Stirling convertors. The second SBIR is for the development of an Adaptive Vibration Reduction System (AVRS) that will essentially eliminate vibrations over a mission lifetime, even in the unlikely event of a failed convertor. This paper discusses the status and results for these two SBIR projects and also presents results for characterizing the friction factor of high-porosity random fiber regenerators that are being used for this application.

\section{SUBJECT TERMS}

Stirling engines; Synchronization; Vibration damping; Regenerators; Friction factor; Nuclear electric power generation

\begin{tabular}{l|c}
\hline 17. SECURITY CLASSIFICATION \\
$\begin{array}{c}\text { OF REPORT } \\
\text { Unclassified }\end{array}$
\end{tabular}

\section{SECURITY CLASSIFICATION OF ABSTRACT}

Unclassified 